\title{
The effect of intensity of intermittent punishment in acquisition on resistance to extinction of an approach response*
}

\author{
DAVID R. LINDEN \\ University of Nebraska, Lincoln, Nebraska 68508
}

\begin{abstract}
In a transfer of persistence paradigm, intensity of shock employed as intermittent punishment during the acquisition of a food-motivated instrumental response was manipulated. While intensities that increased response time during acquisition did increase resistance to extinction, an intensity that had no punishing effect did not increase persistence. The results indicated that there is both a lower and an upper limit to the transfer of an approach response from $s_{p}$ to $s_{f}$ and that these limits should be determined by behavioral rather than intensity measures.
\end{abstract}

Brown and Wagner (1964) and Linden and Hallgren (1973) have demonstrated that approach training with partial reward and intermittent punishment produces increased resistance to extinction. These findings were interpreted as demonstrating a functional similarity between frustrative nonreward and punishment and the anticipatory states that these response-contingent events generate, fractional anticipatory frustration $\left(\mathrm{r}_{\mathrm{f}}-\mathrm{s}_{\mathrm{f}}\right)$ and conditioned fear or fractional anticipatory pain $\left(\mathrm{r}_{\mathrm{p}}-\mathrm{s}_{\mathrm{p}}\right)$. The degree of transfer of an approach response between $\mathrm{r}_{\mathrm{p}}-\mathrm{s}_{\mathrm{p}}$ and $\mathrm{r}_{\mathrm{f}}-\mathrm{s}_{\mathrm{f}}$ must be assumed to be a function of the similarity of these two anticipatory stimulus conditions.

From Wagner's (1969) statement that frustrative nonreward is less aversive than punishment, it follows that lower intensities of punishment will produce greater transfer of persistence to frustrative extinction. Banks and Torney (1969) have concluded that the range of intensities of conditioned fear from which an approach response will transfer to anticipatory frustration is fairly narrow. The purpose of the present investigation was to manipulate the intensity of shock administered on $50 \%$ of the rewarded trials and assess the resultant resistance to extinction.

\section{METHOD}

\section{Subjects}

Twenty-five male and 25 female naive Sprague-Dawley rats obtained from the Charles River Breeding Laboratories served as Ss. These animals were 120-150 days of age at the beginning of the experiment. They were maintained at $75 \%-80 \%$ of their ad lib preexperiment weight by a daily ration of $10-15 \mathrm{~g}$ of Purina Rat Chow given at least $15 \mathrm{~min}$ after each experimental session, water being available ad lib.

\section{Apparatus}

The major apparatus was a straight alley, Hunter Model 385.

*The author wishes to thank Stephen Langdon and Philip Pierce for their assistance in collecting the data. Requests for reprints should be sent to David Linden, Department of Psychology, University of Nebraska, Lincoln, Nebraska 68508.
The runway section was $36 \times 3 \frac{1 / 4}{4} 5 \mathrm{in}$., with start- and goalboxes of $12 \times 3 \frac{1 / 4}{4} 5 \mathrm{in}$. The black guillotine doors of the start- and goalboxes were operated by remote control, and the outside of the transparent Plexiglas walls was covered with black construction paper. A black glass coaster, 2 in. in diam and $3 / 4$ in. deep, was placed against the end wall of the goalbox to serve as a reinforcement cup. Noyes $45-\mathrm{mg}$ pellets were placed in this cup by hand.

The floor of the apparatus consisted of aluminum rods placed at .50-in. center distances. Unscrambled electric shock was delivered to the floor of the goalbox from a Heathkit variable-voltage dc shock supply through 250 -kohm resistance. Shock duration of $.10 \mathrm{sec}$ was controlled by closing one side of the shock circuit through a Hunter silenced decade timer, Model $111 \mathrm{C}$. This timer was started by $E$ via a hand-held pushbutton.

Response times were measured to the nearest $.01 \mathrm{sec}$ by a Hunter KlocKounter, Model $120 \mathrm{~A}$, which was started by the opening of the startbox door and stopped when $S$ interrupted an infrared light beam $.50 \mathrm{in}$. in front of the reinforcement cup.

\section{Procedure}

Ten days prior to the start of the experiment the Ss were placed in individual cages and the daily feeding schedule was initiated. On the 5 days immediately preceding the start of the experiment, each $\mathrm{S}$ was given a 5 -min exploration period in the alleyway. During the last two exploration periods, three or four $45-\mathrm{mg}$ pellets were placed in the foodcup. The $S$ was removed from the apparatus, and the exploration period was terminated whenever these pellets were consumed.

The first 4 days of the experiment consisted of six continuously reinforced trials for all Ss. On each trial $S$ was placed in the startbox oriented toward the door, which was opened 3-5 sec later. Ten seconds after reaching the foodcup and consuming the $45-\mathrm{mg}$ pellet, $\mathrm{S}$ was removed to its home cage for a $10-$ min ITI.

On the fifth experimental day, differential treatment was initiated and continued for 10 days. Group $\mathrm{C}$ continued to receive six continuously reinforced trials each day. Group $N$ received six trials daily, of which reward pellets were presented on three. On the three nonreward trials, $S$ was confined in the goalbox for $10 \mathrm{sec}$ after reaching the foodcup. For the remaining three experimental groups, six continuously reinforced trials were administered each day, and a shock of 125,150 , or $175 \mathrm{~V}$ was delivered approximately .5 to $1.0 \mathrm{sec}$ after $\mathrm{S}$ picked up the $45-\mathrm{mg}$ pellet on half of the trials. (As in the Linden and Hallgren investigation, no $S$ was observed to drop a pellet upon delivery of shock. Nor were any pellets found under the grid floor of the goalbox at the end of any session.) The three trials on which 


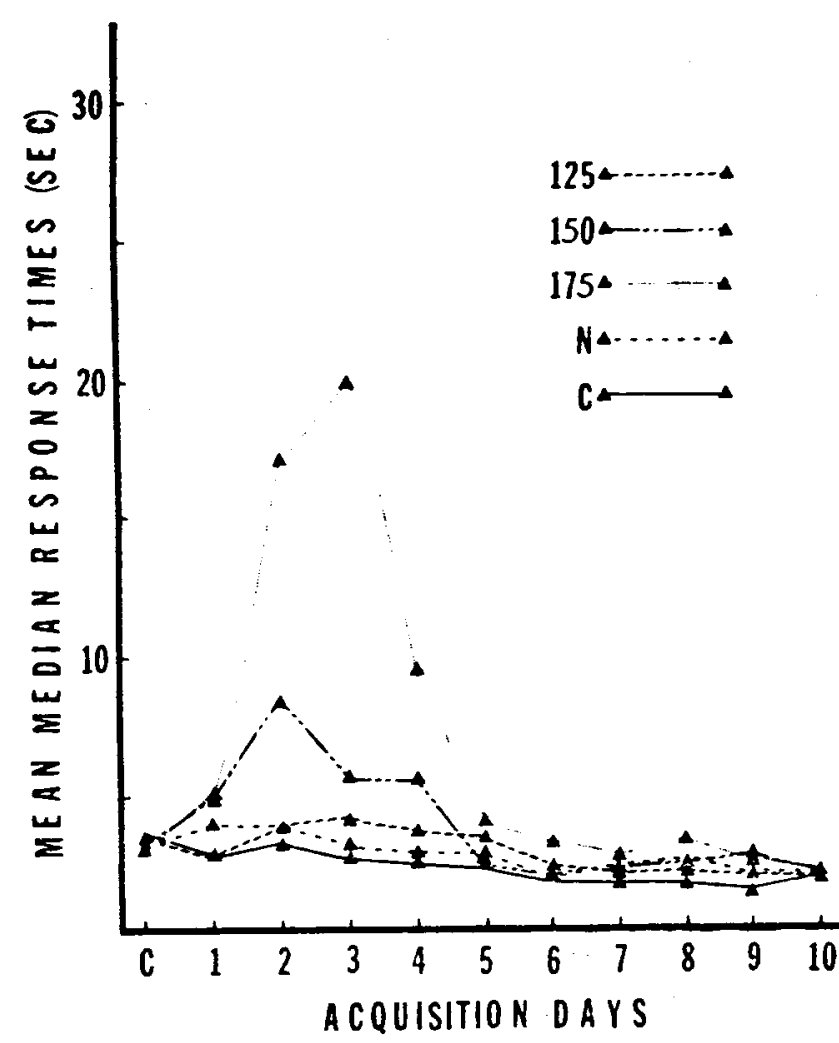

Fig. 1. Mean median response times of the five experimental groups for the fourth session of continuous reinforcement (C) and 10 sessions of differential acquisition.

either nonreinforcement or punishment were to occur were selected randomly prior to each session.

After these experimental treatments, six extinction trials were administered each day for the next 10 days. The Ss were confined in the goalbox for $10 \mathrm{sec}$ after reaching the foodcup. Any $S$ that failed to reach the cup within $120 \mathrm{sec}$ of the start of a trial was removed from the runway to its home cage to await its next trial.

\section{RESULTS}

\section{Acquisition}

The median daily response times of each $S$ were employed in the analysis of the data. Figure 1 presents the mean median response times of the five experimental groups for the 10 daily sessions of differential acquisition. It can be seen in Fig. 1 that the five experimental groups differed over the first 5 days of acquisition but converged so that there was very little difference among the five groups over the last five sessions. An analysis of variance with repeated measures on two factors (Winer, 1971, Case I, pp. 539-559), with treatment between $S s$, and acquisition halves (Sessions 1-5 vs 6-10), within Ss, and sessions within halves was carried out.

The effect of treatment was significant $[F(4,45)=6.21, p<.001]$, reflecting the increased response times of Groups 150 and 175 observed in Fig. 1. The recovery of response time during punishment was demonstrated by a highly significant effect of acquisition halves $[F(1.405)=34.74, p<.001]$ and a significant interaction of this factor with treatments $[F(4.405)=8.23, p<.001]$. Analysis of the simple main effects of treatment indicated that there was a highly significant difference among the five groups during the first five sessions $[F(4,450)=18.14$, $p<.001]$ but not during the second five sessions $[F(4.450)<1.00]$.

The different levels of suppression for the punishment groups and the recovery during the second five sessions of punishment were further demonstrated by Duncan's multiple range tests for the first and second halves of acquisition. During the first five sessions, Groups $\mathrm{N}, \mathrm{C}$, and 125 did not differ from each other (all ps $>.10$ ), while Groups 150 and 175 differed significantly from these three groups and from each other (all ps $<.005$ ). For the second five sessions, there were no significant differences among the five treatment groups (all ps > 10). Thus, it can be concluded that the shock of $125 \mathrm{~V}$ through $250 \mathrm{kohm}$ for $.10 \mathrm{sec}$ had no suppressive effect on running, while 150 and $175 \mathrm{~V}$ had a moderate suppressive effect from which recovery occurred while punishment was in effect.

The main effect of days within halves and their interaction was significant $[\mathrm{F}(4,405)=3.21,2.64$, respectively, $p<.05$ ], while the interaction of Day by Treatments and the three-way interactions approached significance $[F(16,405)=1.64,1.53$, respectively, $.10>\mathrm{p}>05]$. Because days and days by treatments were confounded within halves, the simple main effect of days and the simple interaction were analyzed. For the first five sessions, there was a significant effect of days $[F(4,405)=5.78, p<.001]$ and the interaction of Days by Treatments $[F(16,405)=3.16, p<.005]$, while neither of these factors was significant over the second five sessions $[F(4,405),(16,405)<1.00]$. Thus, it appears that the recovery of response times during punishment was complete by the sixth session and there was no difference among the five groups over the last five acquisition sessions.

\section{Extinction}

Figure 2 presents the mean median response times of the five experimental groups for the 10 extinction sessions. A repeated-measures analysis of variance was carried out on these data with treatment between Ss and extinction sessions within Ss. There were significant main effects of both acquisition treatment $[F(4,45)=15.24, p<.001]$ and extinction sessions $[F(9,405)=59.78, p<.001]$, as well as of their interaction $[F(36,405)=6.55, p<.001]$. A Duncan's multiple range test indicated that Groups 125 and $C$ did not differ significantly $(p>.10)$ and were significantly different from the other three groups ( $p s<.001$ ), while Groups N, 150, and 175 differed significantly from each other (all ps $<.001$ ). 
These results support the hypothesis that varying the magnitude of $s_{p}$ during punished acquisition by varying shock intensity will influence resistance to extinction. The lack of a difference between Groups 125 and $C$ must be attributed to the fact that the $125 . \mathrm{V}$ shock had no punishing effect during acquisition. In this light, the results of the present investigation do agree with the hypothesis that weaker intensities of punishment will produce greater resistance to extinction, with the qualification that the aversive stimulus must have a punishing effect.

\section{DISCUSSION}

The results of the present investigation do support Wagner's (1969) hypothesis that there is a common dimension underlying the aversive response-contingent events of frustrative nonreward and punishment. These results also agree with the conclusion of Banks and Torney (1969) that this transfer is limited to a fairly narrow range of fear intensities. The results of Group 125 indicate that a response-contingent electric shock must have a suppressive effect in order to produce an increase in resistance to extinction. Both Brown and Wagner (1964) and Linden and Hallgren (1973) found that gradually increasing the intensity of intermittent punishment produced some but not a significant suppression of running. Whereas the magnitude as well as the direction of the differences between Groups N, 150, and 175 indicate that an intensity of punishment could be reached which would not increase resistance to extinction and might, in fact, lower it.

The recovery of responding demonstrated by Groups 150 and 175 indicates that these punishing stimuli were of only moderate severity. It may be hypothesized that a punishing shock that is severe enough to prevent recovery of the response while punishment is still in effect may not produce increased resistance to extinction. However, suppression and recovery during punishment are influenced by other variables of the experimental situation as well as by the intensity of the punishing stimulus (Azrin \& Holz, 1966).

Intensities of shock of $125 \mathrm{~V}$ through $250 \mathrm{kohm}$ (approximately $.50 \mathrm{~mA}$ ) for $.10 \mathrm{sec}$ and of less severity have been reported to have a punishing effect, even when given intermittently (Banks, 1966). And such a shock is well above the aversion threshold presented by Campbell and Masterson (1969). Moreover, Church and Raymond (1967) produced response suppression with no recovery using a shock of $.15 \mathrm{~mA}$ for 2 -sec duration when responding was reinforced on a VI 5-min schedule, but only a slight degree of suppression with almost complete recovery when reinforcement was on a VI $1 / 5$-min schedule. The fact that neither of these groups showed increased resistance to extinction over unpunished controls must be interpreted with caution, since positive reinforcement was on an intermittent schedule for all Ss in this study.

The failure of intermittent punishment to increase

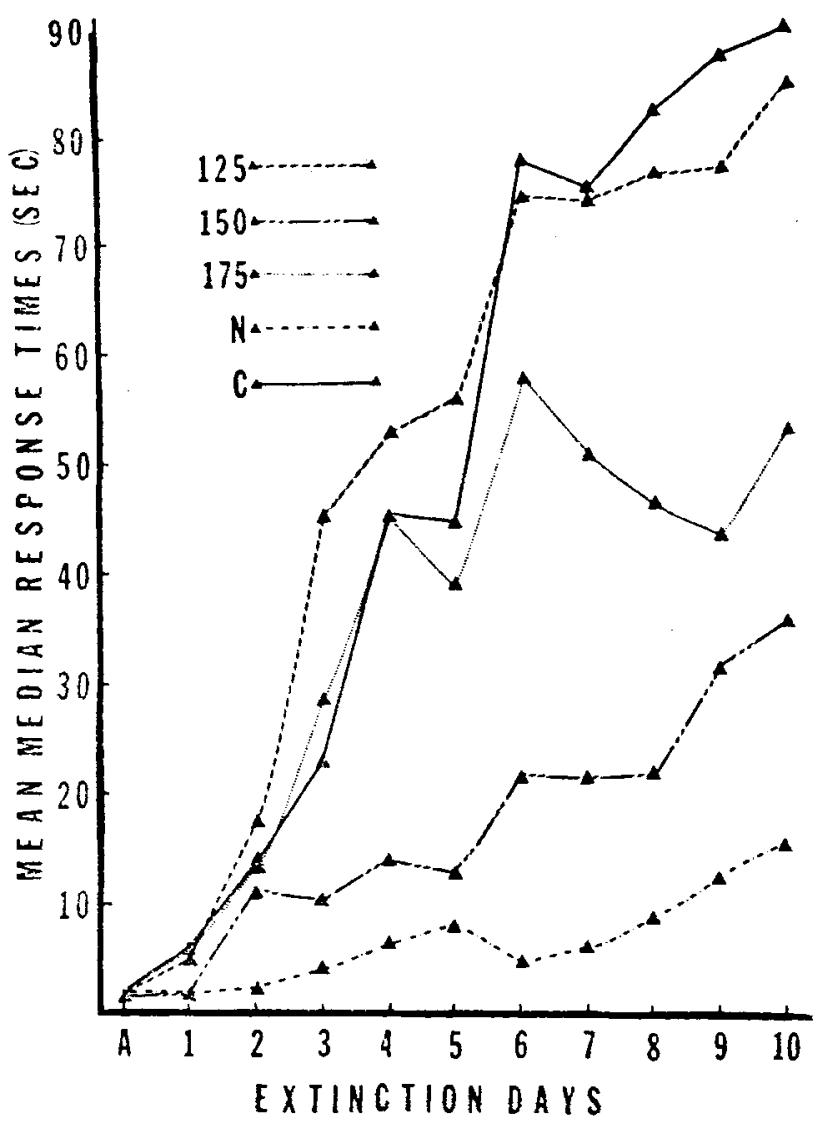

Fig. 2. Mean median response times of the five acquisition groups for the last day of acquisition (A) and the 10 extinction sessions.

resistance to extinction reported by Banks and Torney (1969, Experiment III) may be explained by the lack of a suppressive effect by the intermittent punishment that they employed. These investigators report no significant difference between intermittent punishment and control groups at the end of treatment. Although procedural and $S$ differences must be considered, it does not seem that the intensity and frequency of punishment that these investigators employed (.3 mA for $.1 \mathrm{sec}$ on $15 \%$ of the trials) was sufficient to produce suppression of running during intermittent punishment.

The present results, while supporting the hypothesis that there is a common dimension underlying such aversive response-contingent events as frustrative nonreward and punishment, indicate that the behavioral reaction to punishment may be an important determinant of whether or not it will lead to increased resistance to extinction. They also suggest that transfer of an approach response from $s_{p}$ to $s_{f}$ is better predicted from the disruptive effect of the punishing stimulus in a particular approach training situation than from the intensity of the punishment per se.

\section{REFERENCES}

Azrin, N. H., \& Holz, W. C. Punishment. In W. K. Konig (Ed.), Operant behavior: Areas of research and application. New 
York: Appleton-Century-Crofts. 1966. Pp. 380-447.

Banks, R. K. Persistence to continuous punishment following intermittent punishment training. Journal of Experimental Psychology, 1966, 71, 373-377.

Banks, R. K.. \& Torney, D. Generalization of persistence: The transfer of approach behaviour to differing aversive stimuli. Canadian Journal of Psychology, 1969, 23, 268-273.

Brown, R. T.. \& Wagner, A. R. Resistance to punishment and extinction following training with shock and nonreinforcement. Journal of Experimental Psychology, 1964.68. 503.507.

Campbell. B. A.. \& Masterson, F. A. Psychophysics of punishment. In B. A. Campbell and R. M. Church (Eds.), Punishment and alersive behavior. New York: Appleton-Century-Crofts, 1969. Pp. 3-42.

Church. R. M.. \& Raymond. G. A. Influence of schedule of positive reinforiement on punished behavior. Journal of Comparative \& Pliysiological Psychology, 1967. 63, 503-507.

Linden. D. R. \& Halloren. S. O. Transfer of approach responding between punishment and frustrative nonreward sustained through continuous reinforcement. Learning \& Motivation, 1973. 4, 207-217.

Wagner, A. R. Frustrative nonreward: A variety of punishment? In B. A. Campbell and R. M. Church (Eds.), Punishment and alersive behalior. New York: Appleton-Century-Crofts, 1969. Pp. 157-181.

Winer, B. J. Statistical principles in experimental design. (2nd ed.) New York: McGraw-Hill, 1971. Pp. 539-559.

\section{NOTE}

1. Although there were an equal number of males and females in each experimental group, the fact that they were run separately and by different Es would have confounded any analysis of a sex variable. Therefore, the sex variable and its interactions were pooled into the appropriate error terms of the analyses of variance.

(Received for publication July 16, 1973; revision accepted August 30,1973.) 